Universidade Tecnológica Federal do Paraná - UTFPR

Campus Ponta Grossa - Paraná - Brasil

ISSN: 1981-3686/ v. 08, n. 01: p. 1165-1176, 2014

D.O.I.: $10.3895 / \mathrm{S} 1981-36862014000100003$
Revista Brasileira de Tecnologia

Agroindustrial

\title{
AVALIAÇÃO DE DIFERENTES ÁCIDOS NA COAGULAÇÃO DAS PROTEÍNAS DO SORO DE QUEIJO NO PROCESSO DE FABRICAÇÃO DA RICOTA
}

\section{EVALUATION OF DIFFERENT ACIDS IN THE COAGULATION OF WHEY CHEESE PROTEINS IN THE PROCESS OF RICOTTA PREPARATION}

\author{
Fabiane Antonia Dullius Hauschild ${ }^{1}$; Claudia Capitani ${ }^{1}$; Camila Juliana Friedrich ${ }^{1}$; Daniel Neutzling Lehn ${ }^{1}$; \\ Claucia Fernanda Volken de Souza ${ }^{1}$ \\ ${ }^{1}$ Centro Universitário UNIVATES - Lajeado - Brasil fabianedullius@ bol.com.br; \\ claudiacapitani.f@gmail.com; camilajulianafredrich@hotmail.com; lehn@univates.br; claucia@univates.br
}

\section{Resumo}

O soro de queijo é um subproduto proveniente das indústrias de laticínios e suas características nutricionais como teores de vitaminas, sais minerais, lactose, e principalmente, de proteínas possibilitam sua utilização na produção de novos alimentos. Desta forma, a produção de ricota é uma alternativa viável sob os aspectos ambientais e econômicos para os laticínios, pois possibilita a utilização da matéria-prima na sua totalidade resultando em um produto de qualidade e ainda diminuindo a geração de subprodutos e impactos ambientais. Nesse contexto, a fim de aperfeiçoar o processo de elaboração desse produto, o objetivo desse trabalho foi avaliar as características físico-químicas de ricotas obtidas empregando diferentes ácidos orgânicos no processo de coagulação das proteínas do soro de queijo. As amostras foram elaboradas utilizando os ácidos acético, cítrico, lático e tartárico, sendo determinados os seguintes parâmetros: pH, acidez, atividade de água, umidade, lipídeos, proteínas, e cinzas nos dias 1, 7, 14 e 21 de armazenamento. Os valores de $\mathrm{pH}$ de todas as amostras foram superiores a 5,48 e a atividade de água mínima encontrada foi de 0,965. Os teores de umidade classificam todas as ricotas como queijos de "muita alta umidade", e os teores de lipídeos classificam as amostras como queijos magros ou semi-gordos. Os teores médios de proteínas de todas as amostras foram superiores a 49\%, indicando que a produção de ricota com qualquer um dos ácidos orgânicos avaliados favorece a recuperação das proteínas do soro, agregando valor a este subproduto, contribuindo para a redução do potencial poluidor.
\end{abstract}

Palavras-chave: soro de queijo; ricota; ácidos orgânicos.

\section{Introdução}

O processo de fabricação de queijos gera soro de queijo, obtido após coagulação das proteínas da matéria-prima, através do emprego de ácidos orgânicos ou enzimas proteolíticas. Este subproduto apresenta alto valor nutricional, pois retém parte dos componentes do leite, dentre eles, as proteínas, a lactose, e sais minerais (AFONSO et al., 2009; GIROTO e PAWLOWSKY, 2001; SGARBIERI, 2004).

As proteínas do soro apresentam alto valor biológico, em função da elevada digestibilidade e do perfil equilibrado de aminoácidos essenciais. Esta qualidade nutricional, aliada às propriedades funcionais das proteínas possibilita a utilização do soro na indústria alimentícia para a elaboração de 
novos produtos, como substituto da água ou ingrediente de funcionalidade nutricional ou reológica (SGARBIERI, 2004; TEIXEIRA et al., 2007).

O reaproveitamento do soro de queijo na produção de derivados lácteos é um objetivo das indústrias de laticínios, favorecendo o desenvolvimento de novos produtos e o aspecto econômico, reduzindo o impacto ambiental dos efluentes, principalmente para indústrias de pequeno e médio porte devido ao alto custo das tecnologias avançadas para a reutilização do soro. Uma das formas de reaproveitamento é a produção de ricota (ALISSON, 2008; EGITO et al., 2007; PINTADO e MALCATA, 1999; RAUD, 2008).

A ricota é um queijo suave, não maturado, com pH em torno de 5,8 e composição média de 8 a $12 \%$ de proteínas, $3 \%$ de lactose, $78 \%$ de umidade, e gordura entre 4 a $5 \%$. Devido às suas características, a ricota é um produto que favorece o desenvolvimento de micro-organismos, característica que limita seu tempo de conservação. Por apresentar baixo teor de gordura e boa digestibilidade a ricota é um alimento recomendado para pessoas em dieta, proporcionando quantidade considerável de proteínas. O processo de fabricação da ricota é baseado na precipitação das proteínas do soro através do emprego de calor e ácidos orgânicos, podendo ser elaborada com soro ou uma mistura de soro e leite pasteurizado. O controle das etapas de fabricação, assim como tipo de ácido empregado para a coagulação podem influenciar as características do produto final (FARKYE, 2004; OLIVEIRA, 2009; PORTO et al., 2005).

Dado o exposto, propõe-se neste trabalho analisar as características físico-químicas de ricotas obtidas com o uso de diferentes ácidos orgânicos na etapa de coagulação das proteínas do soro de queijo, e as características sensoriais de ricotas elaboradas com ácido acético em comparação com amostras comerciais do produto.

\section{Material e Métodos}

\section{Material}

O soro de queijo fresco foi cedido pela empresa Hollmann Laticínios Ltda, da cidade de Imigrante, RS. O leite desnatado do tipo UHT foi adquirido no comércio local da cidade de Lajeado, RS. Foram utilizados os seguintes ácidos orgânicos da marca Merck: ácido acético, ácido lático, ácido tartárico cristal e ácido cítrico anidro, todos de grau alimentício. As amostras de ricotas comerciais utilizadas na avaliação sensorial foram cedidas por indústrias da região do Vale do Taquari, RS.

\section{Métodos}

\section{Elaboração das ricotas}

Sessenta litros de soro de queijo foram transferidos para quatro recipientes de inox $(15 \mathrm{~L}$ 
de soro em cada) e submetidos a aquecimento até $65{ }^{\circ} \mathrm{C}$ sob agitação a cada 10 minutos. Após, adicionou-se $10 \%(\mathrm{v} / \mathrm{v})$ de leite desnatado UHT, sob agitação constante para completa homogeneização. A mistura foi então aquecida até $85^{\circ} \mathrm{C}$. A seguir, adicionou-se $0,1 \%(\mathrm{~m} / \mathrm{v})$ de um dos ácidos em estudo (acético, cítrico, lático ou tartárico) por recipiente. O aquecimento foi mantido até a temperatura da mistura atingir $92{ }^{\circ} \mathrm{C}$, permanecendo após em repouso por 30 minutos. A seguir, a massa sobrenadante foi retirada, enformada e submetida à dessoragem sob refrigeração por 24 horas. Em seguida, as amostras foram embaladas em sacos plásticos de polietileno e armazenadas em temperatura de refrigeração de aproximadamente $4{ }^{\circ} \mathrm{C}$ por até 21 dias. A Figura 1 apresenta o fluxograma de elaboração das amostras de ricota.

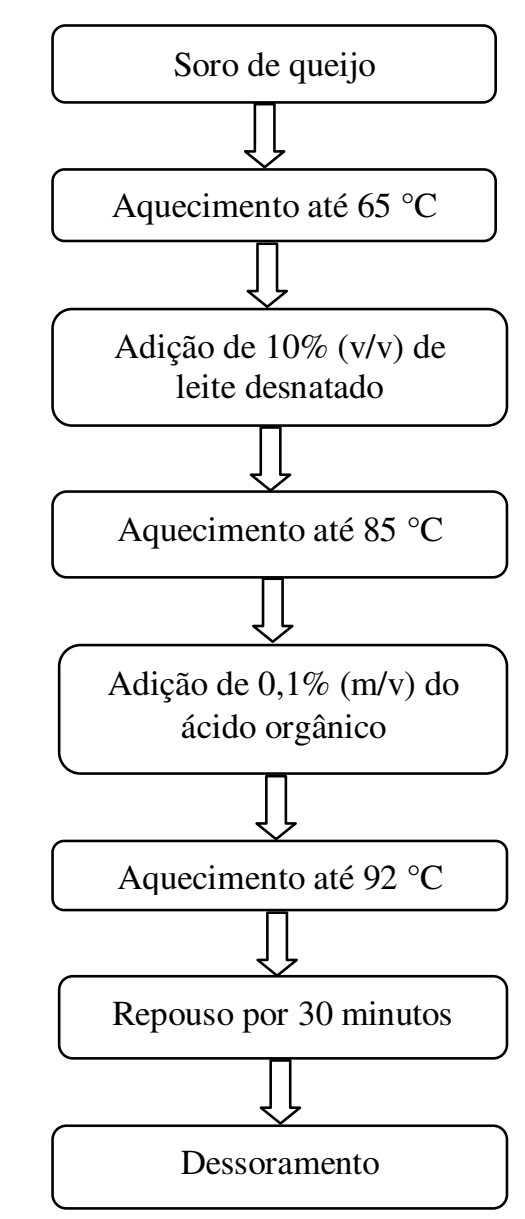

Figura 1 - Fluxograma da elaboração das amostras de ricota

\section{Análises físico-químicas}

Todas as amostras foram submetidas às análises físico-químicas após 1, 7, 14 e 21 dias de armazenamento sob refrigeração. Todas as análises foram realizadas em triplicata. 


\section{Determinação da umidade}

O teor de umidade das amostras foi determinado segundo o método de secagem até peso constante a $105^{\circ} \mathrm{C}$ em estufa marca Quimis, modelo Q-317B-32, conforme Instrução Normativa $\mathrm{N}^{\circ}$ 68, de 12 de dezembro de 2006 (BRASIL, 2006).

\section{Determinação da atividade de água}

A atividade de água foi determinada através do aparelho Aqualab, modelo CX-2, pelo método da AOAC (AOAC, 1995).

\section{Determinação do $\mathrm{pH}$}

$\mathrm{O}$ pH das amostras de ricota foi analisado através da medida da concentração de íons hidrogênio na amostra, utilizando-se pHmetro digital marca Digimed, modelo DM-20, conforme Instrução Normativa $N^{\circ}$ 68, de 12 de dezembro de 2006 (BRASIL, 2006).

\section{Determinação da acidez titulável}

A acidez titulável foi determinada por titulação com solução alcalina de $\mathrm{NaOH} 0,1 \mathrm{~N}$ para neutralização até o ponto de equivalência, utilizando indicador fenolftaleína e expressa em \% ( $\mathrm{m} / \mathrm{m})$ de ácido lático, de acordo com o método descrito na Instrução Normativa $\mathrm{N}^{\circ}$ 68, de 12 de dezembro de 2006 (BRASIL, 2006).

\section{Determinação do teor de proteínas}

O teor de proteínas através da determinação do teor de nitrogênio total pelo Método de Kjeldahl e convertido em proteína bruta pelo fator 6,38, segundo metodologia descrita na Instrução Normativa $\mathrm{N}^{\mathrm{o}}$ 68, de 12 de dezembro de 2006 (BRASIL, 2006), foi realizado em bloco digestor e destilador de nitrogênio, marca Tecnal, modelo TE-0363.

\section{Determinação do teor de lipídeos}

As análises de lipídeos foram realizadas pelo método de Gerber (BRASIL, 2006) no equipamento marca ITR, modelo Super II.

\section{Determinação do teor de cinzas}

As determinações de cinzas foram realizadas em mufla da marca Quimis, modelo Q318M24, conforme metodologia do Instituto Adolfo Lutz (IAL, 2005). 


\section{Análise sensorial}

As amostras de ricota elaboradas com o ácido acético após 1 e 21 dias de armazenamento e duas amostras comerciais de ricota com o mesmo período de fabricação foram submetidas a análise sensorial.

A avaliação sensorial das ricotas para determinar a aceitação do produto foi realizada no Laboratório de Análise Sensorial, em cabines individuais sob luz branca e à temperatura ambiente, com as amostras dispostas em pires branco de porcelana e servidas em bandejas de aço inoxidável. As amostras em porções padronizadas (aproximadamente $10 \mathrm{~g}$ ) foram codificadas com números aleatórios de 3 dígitos e apresentadas aos provadores de forma balanceada e aleatorizada. Junto com as amostras, foi servida água mineral à temperatura ambiente para limpeza do palato e a ficha do teste contendo uma escala hedônica estruturada de 9 pontos, variando de 1 "desgostei muitíssimo" à 9 “gostei muitíssimo". A análise sensorial, através do teste de aceitação, foi realizada por 35 provadores não treinados, recrutados entre os estudantes e colaboradores da Univates, sendo 15 homens e 20 mulheres, com idade entre 20 e 48 anos, os quais avaliaram a preferência em relação aos atributos aparência, aroma, sabor, e impressão global do produto.

Somente participaram da análise sensorial os provadores que assinaram o Termo de Consentimento Livre e Esclarecido (TCLE), conforme Resolução Nº 196 do Ministério da Saúde (BRASIL, 1996) aprovado pelo Comitê de Ética em Pesquisa (COEP) da Univates sob o registro número $\mathrm{N}^{\circ} 029 / 10$.

\section{Análise estatística}

Os resultados físico-químicos e sensoriais foram analisados através da Análise de Variância (ANOVA), e para comparação de médias, o teste de Tukey, em nível de significância de 5\% (p $\leq$ 0,05), utilizando o software STATISTICA versão 7.0.

\section{Resultados e Discussão}

A Tabela 1 apresenta os resultados dos parâmetros físico-químicos das amostras de ricota ao longo dos 21 dias de armazenamento sob refrigeração. 
Tabela 1 - Valores médios da composição físico-química das ricotas durante os 21 dias de armazenamento

\begin{tabular}{|c|c|c|c|c|c|c|c|c|c|c|c|c|c|c|c|c|}
\hline \multirow{3}{*}{ Análise } & \multicolumn{16}{|c|}{ Tempo de fabricação } \\
\hline & \multicolumn{4}{|c|}{1 dia } & \multicolumn{4}{|c|}{7 dias } & \multicolumn{4}{|c|}{14 dias } & \multicolumn{4}{|c|}{21 dias } \\
\hline & $\overline{\mathbf{A}}$ & $\bar{B}$ & $\bar{C}$ & $\bar{D}$ & $\overline{\mathbf{A}}$ & $\bar{B}$ & $\bar{C}$ & $\bar{D}$ & $\overline{\mathbf{A}}$ & $\overline{\mathbf{B}}$ & $\mathbf{C}$ & $\bar{D}$ & $\overline{\mathbf{A}}$ & $\bar{B}$ & $\bar{C}$ & $\bar{D}$ \\
\hline $\mathrm{pH}$ & $5,88^{\mathrm{a}}$ & $5,90^{\mathrm{a}}$ & $5,87^{\mathrm{a}}$ & $5,58^{b}$ & $5,85^{b}$ & $6,09^{\mathrm{a}}$ & $5,87^{\mathrm{b}}$ & $5,65^{\mathrm{c}}$ & $5,88^{\mathrm{a}}$ & $5,85^{\mathrm{a}}$ & $5,79^{\mathrm{a}}$ & $5,60^{\mathrm{a}}$ & $5,85^{\mathrm{a}}$ & $5,48^{\mathrm{a}}$ & $5,67^{\mathrm{a}}$ & $5,65^{\mathrm{a}}$ \\
\hline Acidez titulável (\%) & $0,34^{\mathrm{ab}}$ & $0,34^{\mathrm{b}}$ & $0,38^{\mathrm{a}}$ & $0,34^{\mathrm{ab}}$ & $0,30^{\mathrm{b}}$ & $0,30^{\mathrm{b}}$ & $0,34^{\mathrm{a}}$ & $0,36^{\mathrm{a}}$ & $0,30^{\mathrm{a}}$ & $0,28^{\mathrm{ab}}$ & $0,22^{\mathrm{bc}}$ & $0,20^{\mathrm{c}}$ & $0,28^{\mathrm{a}}$ & $0,26^{\mathrm{a}}$ & $0,26^{\mathrm{a}}$ & $0,24^{\mathrm{a}}$ \\
\hline Atividade de água & $0,986^{\mathrm{a}}$ & $0,978^{\mathrm{b}}$ & $0,981^{\mathrm{ab}}$ & $0,975^{\mathrm{b}}$ & $0,965^{\mathrm{b}}$ & $0,973^{\mathrm{a}}$ & $0,966^{\mathrm{b}}$ & $0,973^{\mathrm{a}}$ & $0,980^{\mathrm{a}}$ & $0,980^{\mathrm{a}}$ & $0,979^{\mathrm{a}}$ & $0,984^{\mathrm{a}}$ & $0,981^{\mathrm{a}}$ & $0,984^{\mathrm{a}}$ & $0,980^{\mathrm{a}}$ & $0,986^{\mathrm{a}}$ \\
\hline Umidade (\%) & $75,8^{\mathrm{b}}$ & $76,3^{\mathrm{ab}}$ & $77,2^{\mathrm{a}}$ & $76,1^{\mathrm{ab}}$ & $78,2^{\mathrm{a}}$ & $75,7^{\mathrm{b}}$ & $76,3^{\mathrm{b}}$ & $75,0^{\mathrm{b}}$ & $75,7^{\mathrm{b}}$ & $76,5^{\mathrm{a}}$ & $75,7^{\mathrm{b}}$ & $76,2^{\mathrm{ab}}$ & $75,5^{\mathrm{a}}$ & $75,5^{\mathrm{a}}$ & $75,0^{\mathrm{ab}}$ & $74,3^{\mathrm{b}}$ \\
\hline Proteínas (\%) & $56,2^{\mathrm{a}}$ & $56,4^{\mathrm{a}}$ & $58,6^{\mathrm{a}}$ & $54,9^{\mathrm{a}}$ & $62,6^{\mathrm{a}}$ & $50,8^{\mathrm{c}}$ & $53,5^{\mathrm{b}}$ & $54,5^{\mathrm{b}}$ & $53,6^{\mathrm{a}}$ & $55,1^{\mathrm{a}}$ & $53,3^{\mathrm{a}}$ & $54,5^{\mathrm{a}}$ & $52,1^{\mathrm{a}}$ & $50,6^{\mathrm{a}}$ & $50,7^{\mathrm{a}}$ & $49,7^{\mathrm{a}}$ \\
\hline Lipídeos (\%) & $23,3^{\mathrm{d}}$ & $23,8^{\mathrm{b}}$ & $24,7^{\mathrm{a}}$ & $23,6^{\mathrm{c}}$ & $25,8^{\mathrm{b}}$ & $27,9^{\mathrm{a}}$ & $24,1^{\mathrm{c}}$ & $22,6^{\mathrm{d}}$ & $23,2^{\mathrm{d}}$ & $28,7^{\mathrm{a}}$ & $27,8^{\mathrm{b}}$ & $23,7^{\mathrm{c}}$ & $27,6^{\mathrm{a}}$ & $27,5^{\mathrm{a}}$ & $27,1^{\mathrm{a}}$ & $26,3^{\mathrm{b}}$ \\
\hline Cinzas $(\%)$ & $3,7^{\mathrm{a}}$ & $3,1^{\mathrm{a}}$ & $4,0^{\mathrm{a}}$ & $2,8^{\mathrm{a}}$ & $4,1^{\mathrm{a}}$ & $3,4^{\mathrm{a}}$ & $3,4^{\mathrm{a}}$ & $3,3^{\mathrm{a}}$ & $3,6^{\mathrm{a}}$ & $3,4^{\mathrm{ab}}$ & $3,1^{\mathrm{bc}}$ & $2,8^{\mathrm{c}}$ & $3,7^{\mathrm{a}}$ & $3,4^{\mathrm{a}}$ & $3,3^{\mathrm{a}}$ & $2,7^{\mathrm{b}}$ \\
\hline
\end{tabular}

Amostra elaborada com: A = ácido acético; B = ácido cítrico; $\mathrm{C}$ = ácido lático; $\mathrm{D}=$ ácido tartárico.

Teores de acidez titulável expressos em \% $(\mathrm{m} / \mathrm{m})$ de ácido lático.

Teores de proteínas, lipídeos e cinzas expressos em base seca.
Médias com letras iguais na mesma linha, para um mesmo período, não diferem significativamente entre si $(p \leq 0,05)$, conforme resultado do teste de Tukey 
Os valores de $\mathrm{pH}$ variaram entre 5,48 e 6,09, não apresentando diferença significativa ( $\mathrm{p} \leq$ $0,05)$ entre as amostras a partir do $14^{\circ}$ dia de fabricação. Outros trabalhos descritos na literatura apresentaram resultados próximos aos deste estudo. Esper et al. (2007) avaliando as características físico-químicas de diferentes amostras comerciais de ricota do município de Campinas, SP obtiveram resultados de pH entre 4,95 e 6,26. Já Resende (2010) avaliou 18 amostras de queijo minas artesanal coletadas em propriedades rurais em diferentes altitudes na região da Serra da Canastra, MG obtendo valores de pH entre 5,20 e 5,52.

Os valores de acidez variaram de 0,20 a $0,38 \%$ durante os 21 dias de estudo. As amostras de ricota fabricadas com ácido cítrico (B) e lático (C) apresentaram diferença significativa (p $\leq$ 0,05) entre si no primeiro dia de fabricação, assim como as amostras produzidas com ácido acético (A) e cítrico (B) diferiram significativamente $(\mathrm{p} \leq 0,05)$ das amostras fabricadas com ácido lático (C) e tartárico (D) no sétimo dia de fabricação. Já a amostra elaborada com ácido tartárico (D) apresentou acidez significativamente $(\mathrm{p} \leq 0,05)$ menor do que as amostras produzidas com ácido cítrico (B) e acético (A) no $14^{\circ}$ dia de fabricação. Não houve diferença significativa $(p \leq 0,05)$ entre a acidez titulável das quatro amostras no $21^{\circ}$ de fabricação. As concentrações de acidez titulável obtidas no presente trabalho são semelhantes aos menores teores encontrados por ESPER et al. (2007), que obtiveram valores entre 0,14 e $0,98 \%$ para as 45 amostras de ricotas (3 lotes de 15 marcas diferentes) comercializadas em Campinas, SP.

Os resultados obtidos demonstram uma pequena redução da acidez titulável entre o $1^{\circ}$ e o $21^{\circ}$ dia de vida-de-prateleira das ricotas. Já o pH entre o mesmo período se manteve praticamente constante para as amostras A e D, enquanto que para as amostras B e C apresentou uma redução. Provavelmente tais resultados são consequência de efeitos combinados como a formação de substâncias que conferem efeito tampão, degradação dos ácidos adicionados e/ou formados durante o armazenamento, liberação de produtos alcalinos provenientes da degradação protéica, e formação de produtos de decomposição não-ácidos (ESPER et al., 2007; SILVA, 2006).

Na Tabela 1 também são apresentados os valores de atividade de água encontrados ao longo do período de vinte e um dias de fabricação, onde as amostras com 14 e 21 dias de fabricação não diferiram significativamente entre si $(\mathrm{p} \leq 0,05)$. Houve variação $(\mathrm{p} \leq 0,05)$ da atividade de água no primeiro dia de fabricação da amostra $\mathrm{A}$ (ácido acético) em relação à amostra D (ácido tartárico), apresentando valores de 0,986 e 0,975, respectivamente. No sétimo dia de fabricação, as amostras A e C não diferiram entre si $(\mathrm{p} \leq 0,05)$, o mesmo ocorrendo como as amostras B e D. Esta variação pode ser influenciada proporcionalmente pelo teor de umidade das amostras analisadas. Resultados deste parâmetro próximos a 1,0 indicam elevada quantidade de água disponível para a proliferação de micro-organismos, acelerando a deterioração do produto (SILVA, 2006). Buriti et al. (2005) avaliaram amostras de queijo minas frescal preparado com a adição de Lactobacillus paracasei, 
encontrando valores de atividade de água entre 0,966 e 0,976, semelhantes aos encontrados nas amostras deste estudo.

O teor de umidade das amostras variou de 74,3 a 78,2\%. Essa variação pode estar relacionada a etapa do dessoramento das ricotas, após a enformagem da massa, ocasionando desidratação heterogênea entre as amostras. De modo geral a umidade das amostras apresentou redução ao longo do período (Tabela 1). Os resultados obtidos segundo a Portaria $\mathrm{N}^{\circ} 146$ do Ministério da Agricultura, Pecuária e Abastecimento (BRASIL, 1996) indicam que as amostras analisadas no presente estudo, se enquadram na classificação de queijo de "muita alta umidade", uma vez que apresentaram valores superiores a 55\%. Modler e Emmons (2001) desenvolveram diferentes formulações de ricota adicionadas de diversas proporções de leite, obtendo valores entre 76,6 a 78,0\%, semelhantes aos encontrados neste trabalho. Outros autores que avaliaram as características de amostras de ricota comerciais observaram uma maior variação entre os teores de umidade. Madalozzo (2010) caracterizou 19 amostras de ricota através de espectroscopia no infravermelho, obtendo valores entre 60,09 e 81,35\% de umidade. Já Souza et al. (2000), que avaliaram as características físico-químicas de 30 amostras de ricota comercializadas em Belo Horizonte, verificaram que uma amostra poderia ser classificada como queijo de "média umidade" (36,0-45,9\%), uma amostra como queijo de "alta umidade" (46,0-54,9\%) e vinte e oito amostras como queijo de "muito alta umidade" (maior que 55,0\%).

Quanto ao teor de proteínas (Tabela 1), o mesmo variou de 49,7 a 62,6\% nas ricotas, com teores médios no período analisado para as amostras A, B, C e D de 56,1\%; 53,2\%; 54,0\%; e $53,4 \%$, respectivamente. Como a utilização do ácido acético no processo de coagulação gerou a ricota com maior teor médio de proteínas no período analisado, este foi selecionado para nova elaboração de amostras para avaliação sensorial. Todas as amostras apresentaram redução no teor de proteínas entre o $1^{\circ}$ e o $21^{\circ}$ dia de fabricação, provavelmente devido a processos proteolíticos (MA e BARBANO, 2003).

As amostras apresentaram teores de lipídeos de $22,6 \%$ a 28,7\%. Com base na Portaria $\mathrm{N}^{\circ}$ 146, de 07 de março de 1996 (BRASIL, 1996), todas as amostras analisadas no vigésimo primeiro dia de fabricação, exprimem valores que as classificam como queijos semi-gordos, contendo porcentagens acima de $24,9 \%$ de gordura no extrato seco. Semelhante ao comportamento dos resultados de umidade, outros autores que avaliaram as características de ricotas comerciais observaram uma maior variação nos teores de gordura que a obtida nesse trabalho. Esper et al. (2007) avaliaram diversas marcas de ricotas comercializadas no município de Campinas-SP, relatando grande variação do teor de gordura no extrato seco, decorrente da falta de padronização no processamento e composição da matéria-prima utilizada, devido à inexistência de um Padrão de Identidade e Qualidade específico para ricota no Brasil. Resultados semelhantes foram obtidos por 
SOUZA et al. (2000) em relação as amostras de ricota comercializadas em Belo Horizonte. Cinco amostras poderiam ser consideradas como queijo magro (10,0-24,9\%), sete amostras como queijo semi-gordo (25,0-44,9\%) e dezoito amostras como queijo gordo (45,0-59,9\%).

Os teores de cinzas das amostras apresentados na Tabela 1 variaram entre 2,7 a $4,0 \%$ do $1^{\circ}$ ao $21^{\circ}$ dia de fabricação, não diferindo significativamente $(\mathrm{p} \leq 0,05)$ no primeiro e no sétimo dias de fabricação. Estes resultados são semelhantes aos encontrados por MACHADO et al. (2004), que avaliaram queijo minas tipo artesanal produzido na região do Serro, Minas Gerais, relatando um teor de médio de $3,79 \%$ para este parâmetro.

Na Tabela 2 são apresentados os resultados da avaliação sensorial das amostras de ricota (amostra elaborada com ácido acético e duas amostras comerciais).

Tabela 2 - Média das notas atribuídas pelos provadores para as amostras de ricotas

\begin{tabular}{|c|c|c|c|c|c|c|}
\hline \multirow{4}{*}{ Atributo } & \multicolumn{6}{|c|}{ Tempo de Fabricação } \\
\hline & \multicolumn{3}{|c|}{1 dia } & \multicolumn{3}{|c|}{21 dias } \\
\hline & \multicolumn{3}{|c|}{ Amostra } & \multicolumn{3}{|c|}{ Amostra } \\
\hline & $\mathbf{A}$ & $\mathbf{E}$ & $\mathbf{F}$ & $\mathbf{A}$ & $\mathbf{E}$ & $\mathbf{F}$ \\
\hline Aparência & $7,26^{\mathrm{a}}$ & $7,43^{\mathrm{a}}$ & $7,29^{\mathrm{a}}$ & $7,54^{\mathrm{a}}$ & $7,34^{\mathrm{a}}$ & $7,66^{\circ}$ \\
\hline Aroma & $5,74^{\mathrm{a}}$ & $4,74^{\mathrm{b}}$ & $4,89^{\mathrm{b}}$ & $5,29^{\mathrm{b}}$ & $5,89^{\mathrm{a}}$ & $5,14^{\mathrm{h}}$ \\
\hline Sabor & $5,40^{\mathrm{a}}$ & $4,40^{\mathrm{b}}$ & $4,80^{\mathrm{b}}$ & $5,14^{\mathrm{b}}$ & $5,86^{\mathrm{a}}$ & $4,94^{\mathrm{t}}$ \\
\hline Impressão Global & $6,80^{\mathrm{a}}$ & $6,06^{\mathrm{b}}$ & $6,91^{\mathrm{a}}$ & $6,34^{\mathrm{a}}$ & $6,20^{\mathrm{a}}$ & 6,54 \\
\hline
\end{tabular}

Não houve diferença significativa $(\mathrm{p} \leq 0,05)$ na aceitação das ricotas para o atributo aparência em ambos os períodos analisados. A amostra A apresentou no $1^{\circ}$ dia de fabricação médias nos atributos aroma e sabor significativamente $(\mathrm{p} \leq 0,05)$ superiores a ambas as amostras comerciais, bem como não diferiu significativamente $(p \leq 0,05)$ da amostra $F$ (comercial) nos mesmos atributos no $21^{\circ}$ dia de fabricação. Em geral todas as amostras de ricota apresentaram boa aceitação, com base nos valores médios do atributo impressão global, superiores a 6,0. A amostra elaborada com ácido acético apresentou em ambos os períodos avaliados a segunda maior nota, 6,80 no primeiro dia e 6,34 no $21^{\circ}$ dia de fabricação, não diferindo significativamente $(\mathrm{p} \leq 0,05)$ da amostra F (comercial).

\section{Conclusão}

Em relação aos teores de umidade, todas as amostras elaboradas com os ácidos acético, cítrico, lático e tartárico podem ser classificadas como queijos de muita alta umidade, com teores de água superiores a 55\%. Os resultados obtidos demonstram que todas as amostras de ricota 
elaboradas possuem teores reduzidos de lipídeos, sendo classificadas no $21^{\circ}$ de fabricação como queijos semi-gordos, segundo a legislação. Os teores médios de proteínas de todas as amostras foram superiores a 49\%, indicando que a produção de ricota com qualquer um dos ácidos orgânicos avaliados favorece a recuperação das proteínas do soro, agregando valor a este subproduto e contribuindo para a redução do potencial poluidor.

\title{
5 Agradecimentos
}

Os autores agradecem a empresa Hollmann Laticínios Ltda. pela doação do soro de queijo. A Fundação de Amparo a Pesquisa do Rio Grande do Sul - FAPERGS e a Secretaria da Ciência, Inovação e Desenvolvimento Tecnológico do Rio Grande do Sul pelos apoios financeiros concedidos a esse trabalho de pesquisa.

\begin{abstract}
The whey is a byproduct from the dairy industry and nutritional characteristics such as levels of vitamins, minerals, lactose, and mainly of proteins allow their use in the production of novel foods. Thus, the production of ricotta is a viable alternative in the environmental and economical for the dairy industry, because it enables the use of raw material in its entirety resulting in a quality product and still decreasing the generation of byproducts and environmental impacts. In this context, in order to improve the process of preparing this product, the aim of this study was to evaluate the physicochemical characteristics of ricotta obtained using different organic acids in the process of coagulation of whey proteins. The samples were prepared using acetic, citric, lactic, and tartaric acid, being determined the following parameters: $\mathrm{pH}$, acidity, water activity, moisture, lipids, proteins, and ash on days 1, 7, 14 and 21 of storage. The $p H$ values of all samples were above 5.48 and the minimum value of water activity was 0.965 . The moisture classifies all the ricotta like cheese of "very high humidity", and the levels of lipids classify samples as low-fat cheeses and semi-fatty. The average content of protein of all samples were above 49\%, indicating that the production of ricotta with any of the organic acids evaluated promotes recovery of whey proteins, adding value to this by-product, helping to reduce pollution potential.
\end{abstract}

Key-words: whey; ricotta; organic acids.

\section{Referências}

AFONSO, W. O.; BIASUTTI, E. A. R.; GERALDI, L. M.; SILVA, V. D. M.; CAPOBIANGO, M. ; PINTO, M. Emprego da hidrólise enzimática utilizando subtilisina para elevar o valor nutricional do soro de leite. Nutrire. v. 34, n. 1, p. 97-114, 2009.

ALISSON, E. Novos ingredientes e tecnologias desenvolvidas por empresas e centro de pesquisas auxiliam indústrias de laticínios a elaborar produtos inovadores e economicamente viáveis. Revista Indústrias de Laticínios. v. 13, n. 77, p. 18-21, 2008.

AOAC - ASSOCIATION OF OFFICIAL ANALYTICAL CHEMISTS. Official Methods of Analysis. Washington, $16^{\mathrm{a}}$ ed., 1995.

BRASIL. Ministério da Saúde. Resolução No 196, de 10 de outubro de 1996. Dispõe sobre diretrizes e normas regulamentadoras de pesquisas envolvendo seres humanos - Conselho Nacional de Saúde do Ministério da Saúde. Diário Oficial da República Federativa do Brasil, Brasília, DF, 16 de outubro de 1996.

BRASIL. Ministério da Agricultura, Pecuária e Abastecimento. Portaria $N^{\circ}$ 146, de 07 de março de 1996. Regulamento Técnico de Identidade e Qualidade dos Produtos Lácteos. Diário Oficial da República Federativa do Brasil, Brasília, DF, 11 de março de 1996, Seção 1, p. 3977-3986. 
BRASIL. Ministério da Agricultura, Pecuária e Abastecimento. Instrução Normativa $\mathrm{N}^{\circ}$ 68, de 12 de dezembro de 2006. Oficializa os Métodos Analíticos Oficiais Físico-Químicos para Controle de Leite e Produtos Lácteos. Diário Oficial da República Federativa do Brasil, Brasília, DF, 14 de dezembro de 2006.

BURITI, F. C. A.; ROCHA, J. S.; ASSIS, E. G.; SAAD, S. M. I Probiotic potential of Minas fresh cheese prepared with the addition of Lactobacillus paracasei. Lebensmittel-Wissenschaft und-Technologie, v. 38, p. 173-180, 2005.

EGITO, A. S.; BENEVIDES, S. D.; LAGUNA, L. E.; SANTOS, K. O. Processamento de ricota a partir do soro de queijos de cabra. Comunicado Técnico N 82, Embrapa. 2007.

ESPER, L. M. R.; BONETS, P. A.; KUAYE, A. Y. Avaliação das características físico-químicas de ricotas comercializadas no município de Campinas - SP e da conformidade das informações nutricionais declaradas nos rótulos. Revista do Instituto Adolfo Lutz, v. 66, p. 299-304, 2007.

FARKYE, N. Y. Acid-heat coagulated cheeses. In: FOX, P.F. Cheese: chemistry, physics and microbiology. London: Elsevier Academic Press. p. 343-348, 2004.

GIROTO, J. M.; PAWLOWSKY, U. O soro de leite e as alternativas para o seu beneficiamento. Brasil Alimentos. n. 10, p. 43-46, 2001.

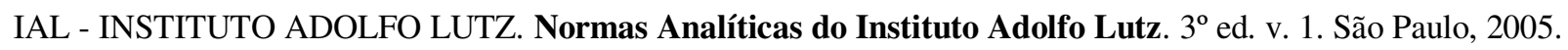

MACHADO, E. C.; FERREIRA, C. L. L. F. ; FONSECA, L. M. ; SOARES, F. M.; PEREIRA JÚNIOR, F. N. Características físico-químicas e sensoriais do queijo minas artesanal produzido na região do Serro, Minas Gerais. Ciência e Tecnologia de Alimentos. v. 24, p. 516-521, 2004. http://dx.doi.org/10.1590/S0101-20612004000400006

MADALOZZO, E. S. Caracterização físico-química de ricotas via espectroscopia no infravermelho e métodos de calibração multivariada. Ponta Grossa, 2010. Dissertação (Mestrado em Ciência e Tecnologia de Alimentos). Universidade Estadual de Ponta Grossa.

MA, Y.; BARBANO, D. M. Effect of temperature of $\mathrm{CO}_{2}$ injection on the $\mathrm{pH}$ and freezing point of milks and creams. Journal of Dairy Science, v. 86, p. 1578-1589, 2003. http://dx.doi.org/10.3168/jds.S0022-0302(03)73743-6

MOLDER, H. W.; EMMONS, D. B. The use of continuous ricotta processing to reduce ingredient cost in 'further processed' cheese products. International Dairy Journal. v. 11, p. 517-523, 2001. http://dx.doi.org/10.1016/S09586946(01)00082-6

OLIVEIRA, M. N. Tecnologia de Produtos Lácteos Funcionais. Editora Atheneu, 2009.

PINTADO, M. E.; MALCATA, F. X. Estudos descritivos e tecnológicos sobre requeijão: caracterização e conservação. Boletim de Biotecnologia. n. 62, p. 19-26, 1999.

PORTO, L. M.; SANTOS, R. C.; MIRANDA, T. L. S. Determinação das melhores condições operacionais do processo de produção da ricota. Boletim do Centro de Pesquisa e Processamento de Alimentos. v. 23, n. 1, p. 173-182, 2005.

RAUD, C. Os alimentos funcionais: a nova fronteira da indústria alimentar análise das estratégia da Danone e da Nestlé no mercado brasileiro de iogurtes. Revista de Sociologia e Política. v. 16, p. 85-100, 2008. http://dx.doi.org/10.1590/S0104-44782008000200008

RESENDE, M. F. S. Queijo minas artesanal da serra da Canastra: Influência da altitude e do nível de cadastramento das queijarias nas características físico-químicas e microbiológicas. Belo Horizonte, 2010. Dissertação (Mestrado em Ciência Animal) - Escola de Veterinária - Universidade Federal de Minas Gerais.

SGARBIERI, V. Propriedades fisiológicas funcionais das proteínas do soro de leite. Revista de Nutrição. v. 17, n. 4, p. 397-409, 2004. http://dx.doi.org/10.1590/S1415-52732004000400001

SILVA, C. R. B. Efeito do uso de Lactobacillus casei como cultura adjunta na qualidade tecnológica de queijo Prato com reduzido teor de gordura. São José do Rio Preto, 2006. Dissertação (Mestrado em Engenharia e Ciências de Alimentos) - Instituto de Biociências, Letras e Ciências Exatas - Universidade Estadual Paulista "Júlio de Mesquita Filho".

SOUZA, M. R.; MORAIS, C. F. A.; CORRÊA, E. S.; RODRIGUES, R. Características físico-químicas de ricota comercializada em Belo Horizonte, MG. Revista Higiene Alimentar. v. 14, n. 73 p. 68-71, 2000. 
TEIXEIRA, L. V.; FONSECA, L. M.; MENEZES, L. D. M. Avaliação da qualidade microbiológica do soro de queijos Minas padrão e mozarela produzidos em quatro regiões de estado de Minas Gerais. Arquivo Brasileiro de Medicina Veterinária e Zootecnia. v. 59, p. 264-267, 2007. http://dx.doi.org/10.1590/S0102-09352007000100044

Submetido em 02 out. 2012, Aceito para publicação em 16 jul. 2013. 